\title{
Newcomers in Educational System: The Case of French-Speaking Part of Belgium
}

\author{
Altay A. Manço, Patricia Alen \\ Institut de Recherche, Action et Formation sur les Migrations, Liege, Belgium \\ Email: amanco@irfam.org
}

Received July $13^{\text {th }}$, 2011; revised September $6^{\text {th }}$, 2011; accepted November $2^{\text {nd }}, 2011$

\begin{abstract}
According to the Lisbon strategy for a knowledge society, entering school plays a significant role for any young immigrant. In Belgium, this issue is very worrying, as equity between native born students and those of foreign origin seems to be lacking. Finally, the situation in French-speaking Belgium is even more difficult than in the Flemish part of the country. Also, this paper aims to explore the strategies in place to welcome and integrate these children. It portrays specific guidance devices for young newcomers and analyzes possible correlations between them and the rate of academic success. In light of particularities of the Belgian educational system especially linked to the fact that we are in a federal state with different languages of reference, our study covers the portion of the federal state where French is the official language. The targeted group is that of newcomers of age to attend secondary school. The method of analysis and synthesis of available information includes both quantitative and qualitative data. Our approach was based on the description and analysis of the context of recognition and knowledge acquisition of young students of foreign origin in secondary education. Our analysis focuses on: accessibility to education and equality of success; adequacy to requirements, consistency and efficiency, as well as effectiveness of the education system; the relevance and specific training of teachers adapted to the newcomers; sustainability of the results: the insertion and future integration of youth; and finally, various linguistic, social and psychological dimensions, as well as citizenship. The report identifies some key elements of the context of schooling for young newcomers and offers brief elements of understanding of the history of immigration in this region. Specific and general practices for integration and schooling of young migrants, including accompanied or unaccompanied minor asylum seekers, are described. Finally, these elements are analyzed in terms of accessibility standards to school education, criteria for adequacy of such education to the specificity of immigrant children and finally, criteria for system effectiveness, and practical tracks are proposed.
\end{abstract}

Keywords: Migrants; Newly Coming Families; Educational System; French-Speaking Part of Belgium; Assessment

\section{Introduction}

According to the Lisbon strategy for building a knowledge society (Rodrigues, 2003), entering school plays a significant role for any young immigrant in Europe. This is not just global social integration, but also the acquisition and valuing of accurate knowledge of these young people required as a part of job search and social mobility. In Belgium, this issue is very worrying as equity between native born students and those of foreign origin seems to be lacking. Indeed, the results of the PISA study (OECD, 2006) show, for example, that school performances of migrant students are poor throughout Belgium. More importantly, no other industrialized nation shows as great a gap between immigrant students and nationals, and the results obtained by these students are among the lowest compared to other European countries. Finally, the situation in Frenchspeaking Belgium is even more difficult than in the Flemish part of the country. Also, this paper aims to explore the strategies in place to welcome and integrate these children. It portrays specific guidance devices for young newcomers and analyzes possible correlations between them and the rate of academic success.

In light of particularities of the Belgian educational system especially linked to the fact that we are in a federal state with different languages of reference, our study covers the French Community of Belgium (FCB) or French Community Wallonia-Brussels, thus this portion of the federal state where French is the official language.

The targeted group is that of newcomers of age to attend secondary school. Officially, this encompasses the 12 to 18 year-old age group. However, since we wish to take into account the transitions primary-secondary-school and secondarygraduate school, this age-frame should be viewed more broadly, especially as the target group falls far behind in school. Our study therefore focuses on youth aged 11 to 20 years.

The method of analysis and synthesis of available information includes both quantitative and qualitative data. The latter are the result of a review of French literature on the subject. It is worth mentioning that hardly any existing document addresses the whole process. Our approach was based on the description and analysis of the context of recognition and knowledge acquisition of young students of foreign origin from thirdcountries in Belgian French-speaking secondary education. Our analysis focuses on the following dimensions: accessibility to education and equality of success; adequacy to requirements, 
consistency and efficiency, as well as effectiveness of the education system; the relevance and specific training of teachers adapted to the newcomers; sustainability of the results: the insertion and future integration of youth; and finally, various linguistic, social and psychological dimensions, as well as citizenship.

The report identifies some key elements of the context of schooling for young newcomers in French-speaking Belgium and offers brief elements of understanding of the history of immigration in this region. ${ }^{1}$ In the following part, specific and general practices for integration and schooling of young migrants, including accompanied or unaccompanied minor asylum seekers, are described. Finally, these elements are analyzed in terms of accessibility standards to school education for young newcomers, criteria for adequacy of such education to the specificity of immigrant children and finally, criteria for system effectiveness.

\section{Elements of Context}

\section{The School Setting}

If under the International Convention on the Rights of the Child, signed and ratified by Belgium, every child has the right to education and if primary education is free for all (article 28), then education is compulsory from age 6 to 18 in Belgium, regardless of the child's status. This implies in particular that a school cannot refuse to register a child in compulsory education, even if he/she is illegal in Belgium.

In Belgium, education is a regional matter, run in the South of the country by the French Community and in the North by the Flemish Community. The compulsory education in the FCB is organized in two parts: basic education (from age 3 to 12, in theory) and secondary education (from age 12 to 18 , in theory).

Basic education is divided into two main stages: pre-school and elementary education. At the end of 6th grade, a common external examination is held in all education networks (public and catholic schools). Success on this exam will result in the issuance of a "Certificate of Basic Studies". However, there is a pedagogical continuity between primary and secondary education. The student who gets his certificate registers in a secondary school of general education. One who fails is oriented towards "first-degree differential education". This is for children who have not mastered basic skills at the end of primary school. It offers small class sizes called "reception class".

For secondary education, there are four mainstreams: 1) general education, 2) technical or arts education transition, 3) vocational or artistic education and 4) professional vocational education. At the end of a 6 year-vocational education, it is possible to pursue a seventh year of specialization to get a degree equivalent to all these sectors in post secondary education and gain access to higher education.

Besides regular education, there are several other types of education: "specialized" for children and young disabled and organized according to 8 types of disabilities; "dual” for youth 15 years and older who wish to combine professional learning and monitoring of general courses part time. "Social advancement" education offers adults the opportunity to pursue graduate school. There are also distance learning and the possibility of graduation before a central board.

${ }^{1}$ For a comparative analysis of the different European countries see http:// www.eurydice.org/Documents/Mig/en/migrants_en.pdf.

\section{Context of Immigration in Belgium}

According to the Centre for Equal Opportunities and the Fight against Racism (2010), migration to Belgium after a lull during the 70 s and 80 s, has resumed to reach a historical high in the mid-2000s: approximately 100,000 people each year arrive in the Kingdom. About $50 \%$ of these people are from another EU country or another European country or an industrialized country (of North America or South-East Asia, for example). The rest of the entries are those of nationals of third countries or countries outside the European Union, often in developing countries.

These people settled mainly in Brussels and the surrounding communities and in Flanders (mainly in economically dynamic cities like Antwerp). Proportionately few newcomers settle in Wallonia where Liege, Charleroi, Mons and Ottignies are centers of attraction. The dispatching plan for asylum seekers ensures that all municipalities of the Kingdom receive migrants, even if ultimately they do not necessarily reside there. This dispatching plan, implemented by the Commissioner General for Refugees and Stateless Persons, raises questions in many ways. On the one hand, little is actually done to avoid concentration of families of new immigrants and asylum seekers in some neighborhoods of large cities. People sent to small rural areas prefer to join members of their communities in cities where housing supply is larger. This concentration is problematic especially in terms of "ghettoization" of some schools. On the other hand, dispatching is almost random and directs families to Flanders while they may be partially French speaking. Impacts on the schooling of children are obvious.

According to the National Register, we can say that in 2010 approximately 40,000 people immigrated in the French Community and 20,000 of them are from third countries in the developing world. This figure is repeated annually with a rising trend (ETNIC, 2010).

\section{Definition of Newcomer}

According to the sociological meaning of the term, the newcomer is an immigrant who recently arrived in the territory of the host country. Some studies establish the threshold as up to two years from the date of actual arrival, others speak of a period of 5, 6 or even 10 years since arrival (UNISOL, 2006). Defining the concept is not easy: people newly arrived in Belgium may know the country, speak its languages, whereas people who immigrated decades ago can experience exclusion. In a family, some members may be longstanding or born in Belgium, while others may not be. In the eyes of the educational system, all of the following conditions have to be fulfilled in order to be considered legally as a pupil/student newcomer:

- Any child at least 2.5 years and less than 18 years;

- Entered the country for less than one year;

- Granted refugee status;

Or who has submitted an application for recognition of refugee status;

Or being a minor accompanying a recognized refugee or one who has submitted an application for recognition of refugee status;

Or being a stateless person or one who has lodged an application for recognition;

Or being a citizen of a country regarded as a developing country or a transitional country. 
According to data from the Centre for Equal Opportunities and the Fight against Racism (2010), age at immigration is very young for many newcomers: $7 \%$ are 0 - 6 years (before compulsory education); $5 \%$ are 6 - 12 years (primary school age); $4 \%$ are 13 - 18 years (high school age); $21 \%$ are from 19 to 25 years (beyond compulsory schooling).

Arguably, French-speaking Belgium receives annually 4500 new migrant students in its system of compulsory education. About half of them (2250) are from a developing country outside Europe. How many are French speaking? Certainly very few, given the fact that even those arriving at a younger age or born in Belgium of immigrant couples are not competent enough in French to succeed easily in school.

In 2007, French-speaking Belgium hosted 63,961 foreign students, of whom more than $51 \%$ came from a country outside the EU. But this does not take into account students who are naturalized Belgians and disappearing from the statistics are people of foreign origin, immigrants from 2nd and 3rd generations who do not fully master written and oral French. In fact, given the high rate of naturalization of immigrant youth, students of foreign origin attending compulsory education in French-speaking Belgium can be estimated at about 145,000 people, half of which are from "third developing countries".

Of the 800,000 children and young people of the French Community subject to compulsory education (6 - 18 years), $18 \%$ are persons of immigrant background. Half the population of immigrants is naturalized Belgian, the other half are foreigners. It is found that less than one percent of the school population is in the country for less than a year. Each time, half the group of young immigrants is from countries outside the European Union and developing countries. Half of this group is boys. These young people today are from countries increasingly diversified, covering the entire globe, representing a significant change in terms of traditional non-European immigrants to Belgium who are people from the Maghreb, Turkey and Central Africa.

\section{Hosting and Orienting Newcomers in French-Speaking Belgium}

\section{Specific Provisions}

Legally, there are several provisions on the reception of newcomer children in primary and secondary schools of the French Community. Some of these provisions are qualitative: they propose a different treatment for these young newcomers from what is usually expected in a school. However, these devices involve few children and they are not long-term. Other measures are quantitative: they can affect each school and thus a large number of children. But they offer very general programs that are not necessarily adapted to the specificity of children newcomers and their needs in terms of education.

The organization of "Bridging Classes" is the main qualitative response of the system to the presence of newly arrived children (CODE, 2010). This is an "educational structure to ensure the reception, orientation and integration of newcomer students in primary or secondary education”. Bridging classes only relate to children in Belgium for less than a year who are either: refugees or stateless persons who applied for recognition of these qualities; minors accompanying a refugee or stateless person recognized or who applied for recognition of one of these qualities. In all cases, these children are citizens of a country considered a developing country or a country in economic transition whose list is prepared by the Ministry of Foreign Affairs. Each child can stay up to one year in a bridging class. These specific classes are organized at the level of primary and secondary education, in various ways, depending on the school. These school locations do not automatically prejudge a large presence of newcomers in the neighborhoods where they operate. On the contrary, in Wallonia, they are created in municipalities where a center for asylum seekers is established. In terms of content, these classes provide, whenever possible, an approach to the French language as a foreign language to these students (Berg, 2009). Methods and special teachers are involved. These classes are also meant, in principle, to facilitate gradual integration and adjustment of these children to life in Belgium (visits, meetings, discoveries, etc.).

The adjustment of coaching norms for students arrived in Belgium for less than three years is the main quantitative response of the system to the presence of newly arrived children. Some children may be denied access to a bridging class because none exists in the school they attend. Schools therefore benefit from special coaching standards for children who cannot access a transitional class despite having that right in theory. Adaptation of coaching standards applies from nursery school: it thus enshrines a right to education from the age of two and a half, that is to say, in pre-school. Also, when calculating the ratio of pupils to teachers in nursery education, a migrant child can count as 1.5 during the three years that this level of education has. In primary education, a migrant student can count fictitiously triple the first two years and double the third. A similar system also exists for secondary education. However, school principals testify that one must be determined to have a child recognized as a "newcomer student”. Administrative denials are not uncommon (Hendrickx, 2004, 2009). The forms to fill out are large and many parents have difficulties in cooperating with the school for various reasons (fear for their status, lack of language or system understanding, missing documents for the child and so on).

Organizing and adapting courses to the language of instruction (ALE-Adaptation à la Langue de l'Enseignement) are an other type of provisions: additional teaching periods are granted by the French Community to schools that accept child newcomers meeting certain conditions, in proportion to their numbers. Indeed, ALE courses aiming at the integration of students in the school system and the acquisition of French can be arranged 3 times a week for the benefit of:

- Stateless students, students of foreign nationality or adopted people who meet the following conditions:

1) Their mother tongue is different from the language of instruction;

2) They have attended primary school organized in the French Community for less than three full years and do not know enough about the language of instruction to successfully adapt to the activities of their class;

3) One of the two parents (or persons to the custody of which they are assigned) does not have Belgian nationality, except in the case of adoption.

- Belgian students satisfying conditions 1 and 2 and whose one parent at least is a foreign national or has acquired Belgian nationality for less than 3 years.

The same limitations as above can be found for the other qualitative measures. Besides, the special teachers in French "foreign or second language" (FLES) are not numerous, and 
neither are the programs to train them that date back to the early 2000s. On top of that, their status is not always recognized and they sometimes lack educational tools (Marrisal, 2004; Maravelaki, 2005; Manço \& Vaes Harou, 2008).

\section{Other Devices and Initiatives}

\section{System-Level Education in the FCB}

In the French Community, school policy is officially based on a philosophy of social equality with the aim of bridging the socio-economic differences between students. In this context, the educational system designs devices to enhance equal opportunities between young people.

The device "positive discrimination" is the most important example. The device known as " $\mathrm{D}+$ " is introduced in compulsory education by the decree of June 30, 1998 to ensure all students equal opportunities for social emancipation, including the implementation of affirmative action. It replaces other older devices such as "Education Priority Zones" inspired from France. Its principle is to "give more to those who have less". In this case, it grants additional resources to schools with students coming from the most vulnerable environments, such as some groups of migrant students. The device applies only to mainstream education at primary and secondary levels in all education networks: public (communities, provinces, cities and towns) and private (denominational or non-denominational). The rules for implementing the decree state that the Government establishes two lists of locations called "positive discrimination", one list for basic education and one for secondary education. These locations may be awarded two types of additional resources: human resources in the form of capital-time or periods-teachers; operating resources in the form of grants or subsidies. Unfortunately, this device does not address directly the origin or the nationality of the students. The distinction of positive discrimination takes place "on the basis of social, economic and educational criteria", but does not take into account cultural and linguistic needs of students (for example the fact that French is not their native language) or the nature of their migration path (uprooting, trauma of precipitation in an unknown environment, etc.).

The First Degree "Differentiated": there are also, since September 2008, at the beginning of secondary education, the classes of first-degree differential. These are classes "preparatory" to the second stage of secondary education for students who have not acquired the basic certification of the primary education. The students are offered a differentiated study course using flexible schedules.

All migrant children cannot be supported by the device bridging classes for many reasons. The singular initiatives of schools and teachers are to be considered. In the Brussels area, for example, the presence of newly arrived pupils has grown to such an extent that there is a severe lack of places. Many schools have set up literacy courses and intensive French such as the Technical Institute R. Cartigny. The school does not have bridging classes but provides an opportunity for a dozen student volunteers to work learning techniques of FLE (French as Foreign Language) after school. This system allows students who do not necessarily meet the criteria of the Government to still benefit from specific training. Manço and Harou (2008) also showed that teachers used to having to teach to the non-French-speaking adapt and tinker for themselves their own approaches and methods at their level with great commitment and generosity.
Unfortunately, they receive little human or material support from education authorities and their experiences are nowhere capitalized. The French community lacks a resource or expertise center in this area.

Note finally, cross-cultural initiatives that are implemented in some schools and courses in language and culture of origin provided to some children in primary and secondary as well as pre-school. These courses are jointly organized in collaboration with the Ministries of Education of the country of origin in parallel with the Belgium education system. This is a partnership program between the French Community of Belgium and seven other countries (Spain, Greece, Italy, Morocco, Turkey, Portugal and Romania) on the language and culture of the country of origin and an intercultural approach to teaching. Other countries like China will soon be integrated into the program. Nearly 180 schools participate in the program "Language and Culture of origin" (LCO). A number of newly arrived children are involved, from Morocco and Latin countries. ${ }^{2}$ Unfortunately, LCO is largely limited to basic education: very few schools organize it in pre-school and it remains exceptional in secondary education. Without being specific to newcomers, language and culture of origin courses may, in some cases, also relate to and complement their reception by the understanding, for example, they can generate on their path of migration. However, it is difficult for children of refugee families to participate in courses provided by the Government of the country they fled.

\section{Extracurricular Support}

Homework schools and other organizations dedicated to youth are present locally in extracurricular activity coaching. According to the law that organizes them, four missions are assigned to homework schools, which are local associations:

1) Intellectual development of children by supporting education, helping with homework and school mediation;

2) Development of social emancipation of the child by an intercultural focus on solidarity and respect for differences;

3) Child's creativity by educating the various dimensions of cultures;

4) Citizenship and participating in civic life.

These initiatives should also be implemented in certain locations determined on the basis of objective criteria, trying to highlight the places heavily affected by job insecurity, school dropout rate and bad housing conditions as well as the presence of population of foreign origin outside the European Union between age 6 to 25. These locations called "Zones d'Actions Prioritaires" (ZAP) therefore take into account the origin as a criterion in defining the places receiving aid, which is not the case for positive discrimination at school.

Gradually, these actions begin to be thought of in a context of integrated control against the phenomena of discrimination against young people of foreign origin. Thus, there are plans for social integration in Wallonia as well as in Brussels, which try to coordinate these scattered actions. "Transversal policies and practices" is a catchword of the moment. Also, even if they are not part of the education sector itself, homework schools closely affect the issues regarding newcomers and their schooling (Sacco \& Rea, 2006). Thus, local associations for assistance

\footnotetext{
"“There is work on the original language but also learning French, says Jamila Zeroual, a Moroccan LCO-teacher, the objective of these projects is to expose kids to cultural differences, but also to promote the integration of these children, even those born in Belgium”.
} 
and, especially, homework schools can reinforce the work of teachers by allowing newcomer students more individualized coaching. Finally, homework school helps to maintain ties with parents who often have few or no contact with the school. In this context, coordination of school and homework school is essential.

Other support structures for youth such as "Action in Open Environment”, in French "Action en Milieu Ouvert” (AMO) or Youth Centers, community centers, centers of expression and creativity, etc. are not left behind in terms of support for young newcomers. These vital aids are not excessive when you think that families need stakeholders who can introduce them to institutions, languages and school systems in Belgium (Manço, Petit, \& Born, 2008).

\section{Unaccompanied Foreign Minors and Young Asylum Seekers: A Particular Issue}

If there is the responsibility of the signatory states to the Geneva Convention of 1951 to accommodate asylum seekers and discuss their applications, specialized services are faced with the management of foreign minors defined as unaccompanied foreign minors (MENA = Mineurs Etrangers Non Accompagnés).

By law, a MENA is “any person under eighteen years, unaccompanied by an adult exercising parental authority or guardianship under the national law of the minor, a citizen of a country outside the European Economic Area and in one of the following situations: have applied for recognition as refugees, do not meet the conditions of access to land and stay determined by law". 3

At the expiration of the statutory period of two times 15 days from the request for recognition of refugee status, during which the youth is welcomed into a temporary shelter in the Brussels region, FEDASIL, the Federal Agency for the Reception of Asylum Seekers, directs the minor to one of the following specialized structures for unaccompanied minors run by itself or its partners: Belgian Red Cross centers or local host structures, in French "Initiatives Locale d'Accueil” (ILA), under the auspices of the Municipal Public Centers for Social Assistance (Centres Public d'Action Sociale or CPAS).

There are seven federal host centers, three Red Cross centers and 12 local host structures providing a suitable home for MENA. The young people are separated from adults, housed in units for girls or for boys and receive appropriate supervision. They stay in an independent group living with their own team of supervisors and educators. Each youth is also assigned a guardian who helps him find a lawyer to apply for asylum or to find a suitable school. Heads of centers or judges often serve as tutors for these young people and are therefore responsible for monitoring them. But there are other tutors and an association brings them together.

The children of asylum seekers and their parents, housed in the similar types of structures, are also face problems of education. The directors of the shelters are talking about a lukewarm welcome of these children into schools in Belgian villages where refugee centers are (Manço \& Vaes Harou, 2008). They are accused of lowering the "level". It is not uncommon, according to these witnesses, that these children should be "parked" all in the same class. FEDASIL as well as the Red

${ }^{3}$ Title XIII, chapter 6 of the law "Tutelle des mineurs étrangers non accompagnés" (24 December 2002).
Cross and the federation of CPAS have developed small teams specialized in advising teachers and educational structure dealing with children of asylum seekers.

\section{Recognition and Knowledge Acquisition of Young Newcomers}

The newly-arrived children and their families are directly affected by a number of policies, and by laws and regulations arising from these policies. These include policies for foreigners and asylum seekers, children of asylum seekers, education and family policies, and health and welfare policies. Each of them is developed within a framework of its own.

In Belgium, the situation becomes more complex because we are a federal state comprising different levels of government, each with special competences. For example, immigration (processing requests for asylum and residence permits) is a federal responsibility, while education is a Community competence. Reception and integration are regional matters. The municipalities also play their role as intermediaries and service providers. This has implications for the consistency and smoothness of the educational experience of young newcomers.

So, overall, we see that the education of children is not a priority in the handling of cases of newcomers. One can meet a series of breaks in the education of children even after their arrival in Belgium. For example, choosing a shelter by the Immigration Department does not take into account the previous studies of children, including the languages in which they have already been enrolled. Then, a family may have to leave the shelter in the current school year. Most often, it changes the city and children change school and sometimes languages of instruction in the middle of a school year. Thus, children who have been educated partly in French in a foreign country are sometimes sent to a shelter in Flanders and are enrolled in Dutch, which does not facilitate their adjustment to school and their schooling. Similarly, expulsions from the territory also occur during the school year. In all these cases, education of children is jeopardized by ruptures that could be prevented if we took more account of the interests of the child and its previous school career as well as the school calendar.

\section{Accessibility Standards and Equal Opportunities: Are Principles Effectively Implemented?}

In the French Community schools, the establishment of special programs for all children, whatever their legal status, has many positive impacts. Based on observations of field professionals (UNISOL, 2006), the vast majority of children of migrant entrants are enrolled, even if they are undocumented. Going beyond compulsory education from age six to eighteen, the programs recognize the importance of a pre-school education. Children are often educated as early as two and a half years old. It seems well established that education and school respond to a right start from an early age.

However, the implementation of specific programs encounters many difficulties. The regulatory systems are effectively planned, but their implementation requires a significant investment on the part of teaching teams to ensure that children benefit the most. This has the consequence that some schools refuse to enroll children in an illegal situation. Indeed, principals must report newly arrived migrant children after gathering the evidence to prove that the child is in the territory for less than a 
year by an official document or written evidence justifying the date of entry into Belgium. The auditors sometimes seem very picky in this area, which can lead to a significant difference between the number of children actually affected and those whose application is accepted. Moreover, it is difficult to include older adolescents (17 - 18 years). Once they are 18, they no longer benefit from compulsory schooling and are no longer protected by the Convention on the Rights of the Child. Additionally, students over 18 years cannot be enrolled in bridging classes, even if they could not complete their schooling in their country of origin. It is difficult to find a school and almost impossible if they are illegal. In addition, children without legal residence are not included in the calculation of the grant of regular schools during the first three months of attendance in school. This, in effect, penalizes schools most often more than three months since we must wait for the next countdown (the counts are done on a fixed date) so that the situation is corrected.

Analysis of the decree "positive discrimination" made by the Free University of Brussels (ULB, 2008) indicates a lack of political will to enhance accessibility of the school to students of foreign origin. Indeed, the terms immigrant, immigration, ethnicity, nationality, origin, foreign, multiculturalism and interculturalism appear nowhere in the decree. The term newcomer is mentioned regarding the socio-economic index to be given to this type of student. The decree on bridging classes for newcomers does address this issue, but involves an extremely small audience. This lack of overall vision of the French Community policies regarding the populations of foreign nationality opposes the very idea of positive discrimination meant to promote opportunities for social emancipation for all students. If a revision of the decree "bridging classes" providing improvements is ongoing, analysis of association claims and various testimonies (schools, students, etc.) shows that this remains below expectations, and that accessibility of the device is not equal for all (Vallet, 2010).

The definition of newcomer has a nationality requirement. Currently, youth who come from countries that are not considered as developing countries by the OECD do not have access to transitional classes. Many children in disadvantaged socioschool situations, from Europe (Eastern Europe, the Balkans, Turkey, Asia and South America), cannot benefit from the device. $^{3}$ Some children arrived in the territory under family reunification or raised in a mother tongue other than French, but with Belgian nationality, are not affected by the various devices.

Another stumbling block: the definition of newcomer excludes candidates to bridging classes who spent a year in Belgium. This poses particular problems for children who arrive in the French Community after residing one year in Flanders or in the German-speaking part of the country. In addition, children cannot benefit from the device over a year. Some newly arrived pupils are accommodated in bridging classes for a period ranging from one week to six months, during which they have a specific framework enabling them to adapt and integrate into the socio-cultural and educational Belgian system. They can then be directed to education that suits them best. Now this time is insufficient to integrate into the Belgian school system, especially for illiterate students and those who suffer from specific difficulties: for example, at the Horta school in Brussels, "the illiterate represent $10 \%$ of our newcomer students who must also be supported by the school. We do not have the means”. In Quebec (Hendrickx, 2004), research has shown that it takes an experience of about a year and a half to ensure that children not attending school integrate into the school system (which includes several levels of learning, including learning French). Francization requires 5 years to reach a "native" level.

The limited number and location of bridging classes raises numerous questions. For primary education, there are 14 schools in Wallonia and 18 in Brussels. For secondary education, 16 schools in Brussels and 13 in Wallonia offer one or more such classes (school year 2010-2011). These classes are necessarily open in schools close to the refugee reception centers. These centers are often outside major cities. For example, in secondary education, a school is located in Liege, one in Charleroi and two of them in Namur. The 9 other schools are in small, even very small towns. No reception class is offered in elementary schools in the Walloon cities. Clearly, the device fails to take into account the non-asylum seeker newcomers or rejected asylum applicants or asylum seekers who do not stay in centers provided for them. ${ }^{4}$

The organization of classes and orientation: the number of students per class is not limited. This can be counterproductive when it is known that some classes have up to more than 40 students. This number should be limited to fifteen children. Moreover, if the existence of the jury of integration is particularly beneficial because it assigns a grade level in the absence of academic record and can guide young people to the end of the transitional class, it also has his flaws. Thus, a study showed that, overall, student skills are undervalued (Manço \& Vaes Harou, 2008). Minors who follow a different procedure are excluded and must absolutely be able to produce a school record (certificate of registration) to request an equivalence in the Ministry (procedure handled by the school). In the case of "undocumented" young people, whose age is estimated medically, they are automatically directed to a sort of preparatory year opening to secondary vocational school, or to third grade vocational. This school guidance imposed on students newly arrived on the basis of a medical test whose reliability has been questioned by many studies (possibility of errors of up to two years, including through bone tests) raises the questions of discrimination and of equality of opportunity.

\section{Adequacy of the Education System to Newly Arrived Pupils and Consistency of the Programs}

\section{Findings in Relation to Young People}

As noted, children who have been educated partly in French are sometimes sent to a reception center in Flanders. The choice of the language area conducted by the Immigration Office at the time of application for asylum families does not appear to take account of the educational experience of children. This reflects the fact that the policies and regulations at the federal level are still not consistent with other practices, for example at the

\footnotetext{
$\overline{{ }^{4} \text { Currently, the decree provides that children under } 18 \text { cannot integrate }}$ bridging class unless they come from an underdeveloped country whose official list was published. This effectively eliminates all students belonging to the European Union, particularly the Portuguese and Spaniards who represent a large community in Saint-Gilles. The immediate future challenges our educational community and raises a number of concerns. Indeed, it is important to note that in 2004, ten new countries will join the European Union and especially Poland. In our classes of newcomers more than $30 \%$ are Polish. It's obvious to me that this is blatant discrimination" (An official of the Athénée Royal Victor Horta, a secondary school with a basic section. These junior high and high school count 620 students including 103 newcomer migrant children, the elementary hosts 40 for a total population of 360 children).
} 
community level. Children's schooling is not a priority in the administrative processing of the social and legal records of newcomers, and at school, the intercultural dimension doesn't seem to be much taken into consideration, if not by the initiative of some teachers (Manço \& Vaes Harou, 2008). Collective initiatives are rare. Yet, academic standards that ignore the diversity lead a significant number of students to construct a relational space-time outside of school, in a no man's land in which markers such as language may be lost.

If the teenager does not master French and knows no English, a translator is present at his arrival to help make presentations and site visits. This translator can be from outside the school or a student of the same nationality as the newcomer or another teacher. However, in many cases, the non French-speaking student is directly immersed in his new class. The student and teacher are at a loss, without any prior information on each other. The presence of translators is not always guaranteed and monitoring by a loved one is not always obvious. ${ }^{5}$

Some young newcomers are in psychological distress on arrival in Belgium. This is explained by the difficulties encountered in their journey of exile (trauma, violence, war), but also by the unstable situation due to cumbersome administrative procedures, and the uprooting and leaving of family. All these sources of stress impact on schooling. They need psychological assistance, but it is not provided. According to a head teacher of the grammar school of Saint-Gilles (Brussels): "95\% of newly arrived immigrant pupils didn't ask to leave and come to Belgium”.

Currently, many teachers are neither prepared nor trained to confront audiences so diverse and fragile except in transitional class where the teaching method proposed is an active teaching communication. This approach gives the learner a central place (Marissal, 2004): "We must encouraged speaking and exchanging, but also group dynamics through presentations, roleplays or other activities. Even more than in an 'ordinary' class, the training group occupies a prominent place. This is why professionals encourage cooperative games to build trust between different children". In fact, we know that these schools are few and cover only a portion of the needs: quarantine bridging classes throughout the country receive less than 1500 youngsters, while the needs are much higher.

The lack of resources and experience should call forth more adequacy and support between schools and external support structures such as homework school or migrant associations. However, the opposite seems to happen. Few extracurricular structures are adapted for teenage migrant newcomers. Homework Schools often compensate for the lack of support structures within schools. In these structures, foreign children are

\footnotetext{
${ }^{5}$ The testimony below illustrates the lack of bridging classes and the numerous administrative difficulties that newcomer children face. A 16-yearoldgirl lives with her aunt in the region of Charleroi. She is seeking asylum. She wants to enroll in general secondary education. We go to the Secondary School of Marchienne-au-Pont (the social worker who followed the family had advised us) where we have an appointment with the school principal. We are very well received. At the time of registration, the head master tells us that he can only enroll Mariama in first grade because she has no documents proving that she has been educated in her country of origin. We leave vexed. I am inquiring... it appears that there is no bridging class in that grammar school. The school where there is one is located several miles away whereas Mariama must pay for her own commute expenses. Fortunately for Mariama, it all ended well: I could contact her former school principal in Guinea and he sent us very quickly all her academic record. She was eventually placed in fourth grade.” (Evidence from A. T. F Newsletter, February 2011).
}

mixed with Natives, but enjoy moments of animation that are reserved for them. We are also witnessing the emergence of homework schools only for the newcomers. As an example, let's mention an association for training in continuing education and professional integration, which also offers a homework school for newcomers aged 12 to 18 . However, these initiatives are not numerous at the secondary level. As for the French courses offered outside school, they are mainly for adults and are conducted during children's school hours.

Moreover, the taking into consideration of the needs or MENA point out another issue on the adaptation of supply to specific target groups. Several refugee shelters develop an approach focused on the needs of MENA. Some results are encouraging. For example, responsible stakeholders for the MENA at the FEDASIL Centre in Florennes are positive. Not only is the rate of absenteeism low, but progress is substantial, particularly in French. Adolescents are aware of the importance that a good education can have on their future. School fees and equipment (often second hand) are supported by the center. However, most unaccompanied minors complain about the look that other students give them when they arrive at school: "It is heavy, especially because of their equipment and clothes (often old, faded, stained, or sometimes with holes). These stigmas betray their origin from a shelter. At the refugee center library in Florennes, three educators are present in the evening to provide follow-up school to MENA. The center of Florennes allows two schools to open bridging classes: the Athénée (grammar school) in Florennes (primary and secondary level), located in the village as well as the Technical Institute of Namur (secondary level), located more than one hour by bus from Florennes. However, the Technical Institute of Namur (ITN) has risen to the challenge of hosting MENA students with enthusiasm. Since 2001, it also organizes a 'bridging class', whose program and management are modulated by the number, origin and level of children in French” (Manço \& Vaes Harou, 2008).

\section{Findings in Relation to Parents}

Evidence suggests that the ethnic diversity of school populations has led to the dilution of contact with parents in many schools. According to a report of the King Baudouin Foundation on The relationship between families and schools (2005), schools justify this by differences in language and culture between parents and teachers. It is true that in such a context, programs and traditional exchanges of information are not enough. The traditional parent teacher conference is less attended and written pieces of information do not produce the desired effect. Some parent groups are not easily reachable by the school. Others are in situations of irregularity or precariousness. This sometimes creates a sense of fear: to go to the school means to them to go to a public institution, a public authority with all the symbolism attached to it. Some schools, however, blame the parents for a certain disinterest in school matters. Asylum seekers, persons engaged in integration difficulties in a new country, poorly informed about the school, may have other priorities and fear of facing the school. They cannot invest the required time and effort to establish a good relationship with teachers. Structures more flexible than schools, homework schools facilitate families/schools exchanges. According to Manço, Petit, \& Born (2006), homework school is seen as a nearby neutral venue where parents can feel more at ease. Most important contacts between homework school and 
the school would allow it to interact with these parents, often forgotten by the school system.

\section{Findings in Relation to Teachers}

Observation of the system allows the question of the consistency of devices: some studies show that teachers who produce extraordinary work with newly arrived children, often not speaking French, are not recognized for these specific skills (Maravelaki, 2004; Manço \& Vaes Harou, 2008). In addition, the system is such that the bridging classes are formed early in the school year by staff, which prevents continuity and carries the risk of demotivation in teachers, besides the loss of experience. Teachers cannot be tenured for such classes and many of them leave these structures, at least hoping to be appointed elsewhere. Yet many engage in specific training (FLE, intercultural education, further university degrees), although these efforts are not reflected in their salary. Transitional class teachers are expressing their frustration at the lack of recognition by the school (by their peers, administration, etc.) for their efforts. Moreover, the courses organized in French "foreign language" are not subject to any specific program. In practice, the organization of classes for illiterate students, FLE, non Frenchspeaking newcomers, is left to the faculty and gives very varied adaptations. This also makes them more difficult to assess in terms of teaching. There is a lack of specific material (exercise books and theory, common database between the schools, information about training).

School structures are often inadequate to support teachers dealing with this specific audience, causing a feeling of worthlessness. Among examples of mismatch, we find the lack of specific training adapted to teachers' needs. Besides the fact that they do not benefit from training to learning "French as a Foreign Language", they have not trained to teach to a diverse and vulnerable audience and face a diversity of backgrounds, native languages and cultures. Also, they must deal with the heterogeneity of a group that includes various levels of academic competence. The strong heterogeneity of the classes of newcomers makes it difficult for the teacher to manage groups and often leaves a large part to volunteering. Moreover, since the arrival of families in the area and enrolling children in schools occur throughout the year, this leads to management difficulties in terms of educational support.

Several studies (Marissal, 2004) show that the problem of violence and tension is not so present in basic education but that it may arise the secondary education. Let's point out the issue of managing conflict among children from communities in conflict (e.g., Russia, Chechnya, ...).

The case of MENA seems to offer a more coherent approach. In Namur, mentor teachers for this audience have taken additional training specific to teaching French as a Foreign Language and as a second language in specialized organizations and universities. Mathematics, technology and science are taught by specialist teachers, tailored to non-francophone students in two levels of complexity. There are also meetings involving various groups of newcomers, and all professors of the transitional class. They are held weekly for two hours to socialize young people and professionals to discuss problems, etc (Manço \& Vaes Harou).

What reading does the teaching staff have of these situations? The teachers interviewed by Maravelaki (2004) highlight several problems relating to their function:
- They believe that there is a lack of coordination between bridging class teachers, but also between teachers in mainstream education.

- Collaboration between institutions is deemed necessary, as well as with other actors such as psychologists, services or hooking up with extracurricular activities to develop the integration of young newcomers and work on problems related to their recent arrival in Belgium (for example: uprooting, poverty, psychological and emotional problems).

- Some regret the lack of specific learning programs in bridging classes leading to a lack of method, even if the transitional class teachers are very motivated. They find it difficult to establish a systematic approach to teaching and nurturing student learning. Often, they use a traditional approach emphasizing teaching grammar and vocabulary, without valuing writing. The methods of teaching French as a foreign language are not widespread; the available documents generally apply to adults and not to school audiences. The material used to teach French in schools abroad is not suitable either.

- Teachers point to a lack of proper assessment of learning for young immigrants.

In fact, we note that the supply of initial training in terms of school support for newly arrived children is totally inadequate, even nonexistent. The few experiences are very late. In continued training, little is provided for teachers in bridging classes, except conferences. Moreover, skills seem to be lacking: most teachers have not received specific training in teaching French as a second language, nor in pedagogy and intercultural communication. In addition, psychological and educational problems posed by newly arrived pupils still require other skills. According to teachers, extra-curricular support centers named "Centres MédicoPsycho-Sociaux” (PMS) get involved only when a problem is referred to them. The survey conducted with students from the University of Liege (Manço \& Vaes Harou) failed to highlight preventive measures: there is no specific assistance upon arrival in the school of a newcomer student. The PMS could yet serve as a link between teachers and newly arrived students, but it seems that this is not usually the case. These teams are also overwhelmed and unprepared for this specific issue.

\section{The Newcomers: An Audience That Confronts the Language, Socio-Educational and Civic Barriers of Our Educational Systems}

According to many testimonies, we see that faced with the complex problems presented by newcomer students, the tasks of social integration and citizenship education supposedly devolved to schools are left to outside structures such as homework school and other associations. Yet, many young immigrant lack benchmarks and support for their cultural education, sport and citizenship. What is, indeed, the usefulness of the presence of children in certain courses if they do not understand what is said? It is important that these children receive individual support in their efforts to socialize in their new country. Places of informal education such as youth facilities and sports clubs can provide excellent socialization areas and locations to practice the French language and strengthen their self-esteem. This applies also to more creative courses, outdoor activities (visits, etc.) and, of course, structures promoting creativity and expression. Partnerships between these organizations and schools, usually desirable, become strategic in regard to newcomers. 


\section{Performance Criteria of the School System and Newly Arrived Students' Achievement: Equality in School Success and Access to General and Higher Education}

Understanding these issues requires establishing an inventory at a global level, including on issues of comparison. The grade repetition rate in French-speaking Belgium is $4.5 \%$ in primary school and $14 \%$ in secondary school. Grade repetition causes a lag in the education of youth. The rate of educational backwardness is not distributed equitably across all categories. According to data from the French Community (ETNIC, 2010) the rate of late students is over $20 \%$ at the end of primary school. This rate is $30 \%$ in the first grades of secondary school, except in the vocational classes, where the rate exceeds $70 \%$ ! Towards the end of secondary schooling, there is a concentration of students of foreign origin (over 50\%) and students with learning delay $(90 \%)$ in the same vocational sections. It is noted that almost all teens that have completed general secondary education go on to higher education. This rate is only 9\% (females) and $16 \%$ (boys) for students in vocational education, although these rates have increased over the previous decade.

One can see that orientation towards general or vocational education is socially determined and contributes to the reproduction of social inequality in relation to the training of young people: data from the French Community (ETNIC, 2010) show that students in general education are overwhelmingly from neighborhoods with a wealthy socioeconomic profile and those in vocational schools are from districts with a precarious profile. Immigrants are widely installed in these neighborhoods. Moreover, the PISA study (OECD, 2006) on math skills, analyzed in the case of Belgium by the staff of the ULB (Jacobs et al., 2007), gives precise information on the quality of education of young immigrants or of immigrants in comparison with native students. According to the study, where native students (Frenchspeaking Belgians) in the 3rd year of high school get 100 points in a standardized test of math skills, students of the second generation (young people born in Belgium to parents born abroad) get 89 points, and immigrant youth (young people born abroad, including newcomers) get 80 points, $20 \%$ less. The tests in reading, in terms of comprehension, science and problem solving confirm these observations. The inequality between natives and immigrants is seen at several levels:

- Among the foreigners, the Turks, the Maghreb and subSaharan Africans have more difficulty than other foreigners (Europeans);

- Young people who immigrated before age 6 (at the beginning of compulsory education) have less difficulty than others;

- In mathematics, the immigrant girls have more difficulty than boys;

- Young people whose parents are immigrants with little education and no skilled jobs encounter more difficulties than others, but in all cases, immigrants have more difficulty than young people of the second generation and native;

- Young people whose parents use the language of instruction at home have fewer problems than other immigrants;

- Young people in Flanders have fewer problems than youth in the French Community in all categories;

- Finally, immigrant youth attending vocational schools have more difficulty than others in the same category.

These results identify, first, an effect related to the stream- lining of our teaching system, reserving vocational classes to inner-city youth (with a strong immigrant presence). Secondly, the results suggest an effect of the system related to the language of instruction. This is not the native language of most immigrant children and students of foreign origin. Acting as if it were promotes inequality for immigrants. Indeed it appears that the worst results are obtained on the reading test. Finally, note that there are no further findings on the education of immigrant children in Belgium. The French Community does not publish them, notwithstanding the difficulty of the task. We see further evidence of the political indolence about the diversity represented by children of diverse backgrounds in our schools. If we do not face up to the educational challenges posed by this diversity, we will only worsen the already existing inequality.

\section{Summary of the Findings and International Overview}

The educational situation of second generation and migrant children in Belgium remains problematic. Differences in achievement between natives and migrants are important, even for children of the second generation. Although not essentially different from that of disadvantaged children in Belgium, the situation with regard to school of children from the recent waves of immigration in Belgium is of concern because the situations of failure are especially acute and subjected to more tension of a cultural type. Yet school integration is probably the factor that determines the most the different forms of social and economic integration. It is measured by the quality, quantity and content of the studies followed, as well as by success in them. The crowning of studies by the required qualifications, the low number of wasted years, the choice of valued directions and the high level of skills reached by the end of training are the criteria for quality integration. Added to this, of course, is the opportunity for youth to occupy and secure meaningful employment in their chosen vocation.

While the hosting programs for newly arrived migrant children has been studied repeatedly, little analysis and data exist regarding the success rates of these youth. When these data exist, they focus more specifically on the notions of performance as shown by the analysis of the results of the PISA study. This indicates that the achievement of pupils of foreign origin is poor throughout Belgium. In fact, no other industrialized nation displays as great a gap between students from immigrant families and others, and the results obtained by students of foreign origin are among the lowest in developed countries, despite the high rate of naturalized children compared to Germany, Luxembourg or Switzerland. The two communities in Belgiumand especially the French community-must undertake considerable efforts to democratize the education system, which currently does not promote social mobility. Desegregation policies should play an important role even if they are not sufficient to reduce social inequalities in the education system.

Beyond these indications of performance, quantitative and qualitative data on the success rate, integration or effective orientation are rare. However, the studies reviewed allow us to identify the following findings:

- Students often have difficulties in written language.

- Submitted to this schooling poorly adapted to their situation, migrant children often fail and are relegated to vocational classes. These classes are little valued in Belgium for not opening to higher education.

- We note that teenagers often find themselves in vocational 
sections or reception classes, because the level is less demanding and it gives them more time to learn French. But these guidelines often do not take account of the children's actual skills and the expectations of their families about school counseling.

- The prospect of a bridge toward general education, although announced, seems not to exist. According to teachers, a reorientation to "general" education is rarely considered because the level of these students in French is too low or their educational backwardness too high. Thus, unless a very strong motivation to hard work exists, these students often find themselves "trapped" in sectors that do not always match their abilities or intentions and their earlier education.

- The responsible stakeholders for MENA seem to have a positive outlook regarding the education of youth. In all cases, young newcomers develop a certain command of French and some awareness of the importance that a good education can have for their future.

\section{Conclusion and Practical Tracks}

Increasing socio-cultural diversity and equity within the education system are both necessary and urgent objectives in Belgium. Indeed, the results of the PISA survey show a wide disparity between native students (French and Flemish) and immigrants of the first and of the second generation. For example, the average Belgian students in reading (but also in mathematics) is more advanced (about two school years), compared with the average score for non-European migrant students enrolled in the country. Apart from the PISA study, there are very few evaluations available on the issue of inclusion and integration (professional and social) of newcomers in the CFB in terms of sustainability. But without this, it is difficult to identify indicators corresponding to the dimensions of effectiveness, efficiency, success, or even citizenship. In addition, the teaching and learning proposals mentioned are rarely assessed in the short and long term. Similarly, the effects of the long-term action-research are not checked to generalize their teaching practices (Crutzen \& Lucchini, 2007).

However, there is a plethora of reports and articles providing an analysis of relevant devices for receiving newcomers as such, mainly that of the bridging class. If it deserves to exist, the system as it is today has many shortcomings and all professionals agree that it is urgent to change it. The synthesis of their views allowed us to identify indicators relating to dimensions of equal opportunity and accessibility, consistency and adequacy of practices to the needs of young people, teachers and parents and finally, to a lesser extent, the relevance of teaching staff who work there now. Despite the limitations outlined, we could provide a synopsis of the findings and indicators. It is based on key elements of it that we are trying to make tracks and recommendations to optimize the educational integration of newcomers. We group them into three main groups: accessibility criteria to structures and equal opportunities, consistency of the devices and, finally, relevance of the education system.

Firstly, if we want to reduce discrimination, the admission criteria should be reviewed to allow more children to benefit from an adapted coaching and optimize their chances of integration. Moreover, learning French should be allowed to continue beyond the transitional class. Indeed, all newcomer pupils have different courses of study and levels of schooling: some have never been literate, while others come from countries where the alphabet is totally different from ours. Therefore, there should be opportunities for extension of access to bridging classes. Finally, the offer of bridging classes in terms of public and location must be expanded and the number of students per class limited.

Then, the content and methods need to be reviewed, but also systematized to provide consistent practices with regard to the needs of youth. Priority should be given to learning French-as a foreign language - a major condition for the integration of a new culture and new learning. Organizing a system of "mentoring" with the intervention of outsider stakeholders or tutoring in French could be some of the practices to retain (Crutzen \& Manço, 2003). Many examples have shown the importance of establishing a relationship of trust with the child that ignores "academic performance" in the beginning. As such, techniques like drama have proven effective because the learning it generates is transdisciplinary: looking, listening, thinking, behaving in a group and, above all, in class, learning methodically and discussing. There is also a lack of consistency with the psychological profile of that audience. Indeed, the trauma experienced in the country of origin, which often continues well into the host country to the extent that they live both a tearing away from one culture and a culture shock in one other, implies the need for the establishment of specific support both psychological and intercultural. The issue of improving the expertise and training (initial or ongoing) of teachers also remains significant. It begins with regularizing the status of those specializing in care for newly arrived children, an issue that has implications for their motivation. Then training programs designed for them should be put in place. Teachers are facing a great challenge: to accompany an at best heterogeneous and vulnerable public and to build an intercultural dialogue. Surely this great challenge is sufficient to justify the establishment of training in FLE (Foreign language French) first, and training in intercultural education secondly to help them manage their diverse classrooms.

Finally, we must not neglect the after school framework that plays a major role in supporting both young people and parents. It was found that at this stage taking into account socio-cultural missions and civic education at school is often relegated to homework schools. We must therefore redefine the role and place of the school on these dimensions, in conjunction with its partners in civil society. Indeed, the needs are wide and the school cannot assume all of them alone. Therefore, cooperation between the various structures and institutions (PMS, homework schools, MENA centers, civil society, and so on) should be preferred to ensure a transversal approach that will lead to mutual enrichment of the different professionals and take better consideration of the needs (legal, medical, psychological and social) of young newcomers and their families.

\section{Acknowledgements}

The authors thank A. Willaume, E. Montfort, N. Jeunehomme, L. Molina, M. Villan and A. Grégoire (Nouveau SaintServais) for their help.

\section{REFERENCES}

Berg, I. (2009). Quel français enseigner aux primo-arrivants? Traces de changements, 190.

http://www.changement-egalite.be/spip.php?article1380

Centre pour l'Egalité des Chances et la Lutte Contre le Racisme (2010). 
Migrations, Rapport annuel 2009, Brussels.

CODE (2010). Les classes passerelles: ce qui doit être amélioré, Brussels.

Crutzen, D., \& Lucchini, S. (2007). Etat des savoirs concernant l'éducation et la scolarité des enfants issus de l'immigration en Communauté française de Belgique. In M. Martiniello, \& A. Rea (Eds.), L'Immigration et intégration en Belgique francophone. Etat des saviors (pp. 287-332). Louvain-la-Neuve: Academia Bruylant.

Crutzen, D., \& Manço, A. (2003). Compétences linguistiques et sociocognitives des enfants de migrants. Turcs et Marocains de Belgique. Paris: L'Harmattan.

ETNIC (2010). Les indicateurs de l'enseignement, 5. Brussels: Communauté française de Belgique.

Hendrickx, M. (2009). Accueillir les pirmo-arrivants. Eduquer, 70, 29-35.

Hendrickx, M. (2004). Dossier spécial primo-arrivants. Les Nouvelles de l'Observatoire, 49, 6.

Jacobs, D., Rea, A., \& Hanquinet, L. (2007). Performances des élèves issus de l'immigration en Belgique selon l'étude PISA. Une comparaison entre le Communauté française et la Communauté flamande. Brussels: Fondation Roi Baudouin.

Manço, A., \& Vaes Harou, A. (2008). Elèves non francophones dans le cycle secondaire en Communauté française de Belgique: Enseignements d'une recherche-formation. Diversités et Citoyennetés, 13, 5-19.

Manço, A., Petit, S., \& Born, M. (2008). Devenir immigré: Rôles des structures sociosanitaires dans le trajectoire d'exil des familles réfugiées: Le cas de la Belgique francophone. In M. Vatz-Laaroussi et al. (Eds.), Familles migrantes au gré des ruptures: Tisser la transmission (pp. 257-277). Lyon: L'interdisciplinaire.

Maravelaki, A. (2005). L'accueil des élèves primo-arrivants à l'école secondaire. Quelles implications pédagogiques et politiques pour un soutien efficace. Centre de recherche en didactique des langues et literatures. Louvain-La-Neuve: UCL.

Marrisal, V. (2004). Primo arrivants. Apprentissage et découverte de la langue. Lettre d'information de la Coordination des Ecoles de Devoirs de Bruxelles, 88, 2-15.

OECD (2006). Where immigrant students succeed. A comparative review of performance and engagement. Paris: OECD.

Rodrigues, J. M. (2003). European policies for a knowledge economy. Cheltenham: Edward Elgar.

Sacco, M., \& Rea, A. (2006). Le fonds d'impulsion à la politique des immigrés (FIPI): Etat des lieux en Belgique francophone, Brussels: Ministre de la Fonction publique, de l'Intégration sociale, de la Politique des Grandes Villes et de l'Egalité des chances.

ULB (2008). Instruments pour élaborer une politique à l'égard des populations d'origine ou de nationalité étrangère en Communauté française de Belgique. Rapport Final, Brussels.

UNISOL (2006). Recomposer sa vie ailleurs. Recherche-action auprès des familles primo-arrivantes. Paris: L'Harmattan.

Vallet, C. (2010). Réforme des classes passerelles: Un décret qui sait se faire attendre. Alter Echos, 294, 18-19. 